\title{
Esophageal Gastrointestinal Stromal Tumors Presenting as Mediastinal Mass
}

\author{
M. Kafeel N.K.S. Cheedella J.C. Wang \\ Division of Hematology/Oncology, Brookdale University Hospital Medical Center, \\ Brooklyn, N.Y., USA
}

\section{Key Words}

Esophageal gastrointestinal stromal tumors · Mediastinal mass · Sarcoma

\begin{abstract}
Gastrointestinal stromal tumors (GISTs) are the most common mesenchymal tumors of the gastrointestinal tract and are predominant in the stomach and intestine but rare in the esophagus. Here, we report a case of esophageal GIST which presented as a mediastinal mass on chest X-ray and dyspnea. The case was initially diagnosed as leiomyosarcoma, which could create a diagnostic dilemma. Therefore, recognizing this uncommon presentation as a mediastinal mass with esophageal GIST is important in the differential diagnosis.
\end{abstract}

(C) 2013 S. Karger AG, Basel

\section{Introduction}

Gastrointestinal stromal tumors (GISTs) are the most common mesenchymal, nonepithelial tumors of the gastrointestinal tract in adults between 40 and 50 years of age $[1,2]$. As per SEER analysis, only $1 \%$ of 1,458 GIST cases are esophageal in origin, with an incidence of $51-70 \%$ in the stomach; $25-36 \%$ in the small intestine; $5-7 \%$ in the colon, rectum and appendix, and 1-3\% in the esophagus [1-3]. Esophageal GISTs typically occur in the middle to distal third of the esophagus. They are generally small and asymptomatic, but occasionally can be large and produce dysphagia. A review of the literature revealed a case of a large esophageal GIST presenting with dyspnea [4]. However, here we report a rare case of a small esophageal GIST in a patient with dyspnea who presented with a mediastinal mass on chest X-ray and was initially diagnosed by a pathologist as having leiomyosarcoma and referred for chemotherapy. 
Kafeel et al.: Esophageal Gastrointestinal Stromal Tumors Presenting as Mediastinal Mass

\section{Case Report}

A 73-year-old female presented with vague cough and dyspnea on exertion. She was previously healthy with no pulmonary or heart problems. There was no history of odynophagia, dysphagia or weight loss. Initial chest X-ray showed a mass in the mediastinum (fig. 1). A CT scan of the chest with contrast revealed a hypodense, soft tissue mass/lymphadenopathy in the posterior mediastinum measuring $2.0 \times 3.0 \mathrm{~cm}$, contiguous with the esophagus (fig. 2), suggestive of neoplastic etiology. Further imaging with PET revealed a mediastinal soft tissue mass/lymph node and a standardized uptake value $\left(S_{U} V_{\max }\right)$ of 5.1 .

The patient underwent a bronchoscopy and mediastinoscopy with fine-needle aspiration of the mass. Pathology showed increased cellularity with moderate nuclear atypia and pleomorphism with a mitotic count of 2-3 mitoses/10 high-power fields. Immunohistochemistry was positive for vimentin, SMA, caldesmon and desmin. EMA was focally positive and there were a few positive CD34 cells. It was negative for S100, AE1/AE3 and CD68. The Ki67 index was 3-5\% and, finally, the sample was reported as spindle cell well-differentiated leiomyosarcoma (fig. 3). The patient was referred to us for further management.

Given the possibility of a GIST, CD117 immunostaining was requested and yielded a positive result (fig. 4). Then, the patient underwent bronchoscopy with right thoracotomy and esophagoscopy. Esophagoscopy and double lumen bronchoscopy were unremarkable. Thoracotomy findings showed the mass in the posterior mediastinum, which was dissected free from the trachea and inferior aspect of the aorta. The tumor involved muscle layers of the esophagus but not the mucosa. Six weeks after surgery, a repeated PET-CT scan showed no recurrence. On further follow-up, she was free of dyspnea and is currently under surveillance.

\section{Discussion}

GISTs are rare, accounting for $0.1-3.0 \%$ of all gastrointestinal neoplasms and $5.7 \%$ of sarcomas [5]. Initially, 'GIST' applied to neoplasms displaying only c-kit (CD117), but the diagnosis is based on histopathology and immunohistochemistry [6]. A total of $95 \%$ of GISTs express KIT or DOG 1 and have mutations in KIT or platelet-derived growth factor receptor, $\alpha$ polypeptide [7]. The KIT-positive cells in abdominal soft tissues include mast cells in the wall of the gastrointestinal tract; the interstitial cells of Cajal (intestinal pacemakers) around the myenteric plexus were thought to be the origin of GISTs.

GISTs typically present in adults 40-50 years of age and predominantly in the stomach and intestine. Rarely, esophageal GISTs are encountered. A comprehensive review of 11 case reports (table 1) and case series with esophageal GISTs showed that only 1 patient presented with dyspnea and a large posterior mediastinal mass $(27 \mathrm{~cm}) ; 3$ further masses were detected on routine chest X-ray $[3,4]$. Our patient presented with vague, progressive shortness of breath, with the unusual finding of a small mediastinal mass on chest X-ray.

Esophageal GISTs commonly present with dysphagia but bleeding, perforation, back pain, anorexia, regurgitation and weight loss have been reported. Dyspnea with the finding of a small tumor on chest X-ray is rare. Further, PET-CT can help to differentiate GISTs from sarcoma, but our case showed an $\mathrm{SUV}_{\max }$ of 5.1 which can misclassify it as sarcoma $[3,8]$.

Initial biopsy and testing created a diagnostic dilemma because immunohistochemistry did not include CD117 immunostaining and diagnostic imaging was inconclusive. We present this case to raise physician awareness of such a rare presentation, so that the 
possibility of GISTs is considered in these situations, and CD117 testing be done if sarcoma histology is obtained.

Surgery is the mainstay of treatment of localized GISTs; targeted therapies like imatinib have shown overall survival benefit in high-risk patients after surgery $[9,10]$. And in unresectable and metastatic disease, it has been approved as primary treatment. FDG-PET is helpful in assessing tumor response versus progression [10]. The PDGFRA mutation D842V, sporadic wild-type GISTs, mutations with succinate dehydrogenase or BRAF-mutated GISTs are unlikely to respond to imatinib [9].

Sunitinib is used as second-line treatment in advanced imatinib-failed patients. Ongoing trials involve sorafenib, nilotinib, pazopanib, regorafenib and cediranib for advanced GISTs [11-15]. Future trials with combined or sequential use of tyrosine kinase inhibitors with other medications and personalized therapy after tumor molecular subtyping are promising in the management of GISTs [16].

\section{Conclusion}

Esophageal GISTs presenting with dyspnea and no dysphagia are rare. Our case report highlights the consideration of GISTs in the differential diagnosis of posterior mediastinal masses and emphasis on the necessity of CD117 staining in those situations which can alter the therapeutic and prognostic implication for the patient.

\section{References}

1 Miettinen M, Lasota J: Gastrointestinal stromal tumors (GISTs): definition, occurrence, pathology, differential diagnosis and molecular genetics. Pol J Pathol 2003;54:3-24.

-2 Tran T, Davila JA, El-Serag HB: The epidemiology of malignant gastrointestinal stromal tumors: an analysis of 1,458 cases from 1992 to 2000. Am J Gastroenterol 2005;100:162-168.

-3 Miettinen M, Sarlomo-Rikala M, Sobin LH, Lasota J: Esophageal stromal tumors: a clinicopathologic, immunohistochemical, and molecular genetic study of 17 cases and comparison with esophageal leiomyomas and leiomyosarcomas. Am J Surg Pathol 2000;24:211-222.

4 Basoglu A, Kaya E, Celik B, Yildiz L: Giant gastrointestinal stromal tumor of the esophagus presenting with dyspnea. J Thorac Cardiovasc Surg 2006;131:1198-1199.

5 Burkill GJ, Badran M, Al-Muderis O, et al: Malignant gastrointestinal stromal tumor: distribution, imaging features, and pattern of metastatic spread. Radiology 2003;226:527-532.

6 Fletcher CD, Berman JJ, Corless C, et al: Diagnosis of gastrointestinal stromal tumors: a consensus approach. Hum Pathol 2002;33:459-465.

7 Bachet JB, Emile JF: Diagnostic criteria, specific mutations, and genetic predisposition in gastrointestinal stromal tumors. Appl Clin Genet 2010;3:85-101.

8 Chang WC, Tzao C, Shen DH, Cheng CY, Yu CP, Hsu HH: Gastrointestinal stromal tumor (GIST) of the esophagus detected by positron emission tomography/computed tomography. Dig Dis Sci 2005;50:13151318.

-9 Blay JY, Le Cesne A, Cassier PA, Ray-Coquard IL: Gastrointestinal stromal tumors (GIST): a rare entity, a tumor model for personalized therapy, and yet ten different molecular subtypes. Discov Med 2012;13:357367.

10 Choi H, Charnsangavej C, Faria SC, et al: Correlation of computed tomography and positron emission tomography in patients with metastatic gastrointestinal stromal tumor treated at a single institution with imatinib mesylate: proposal of new computed tomography response criteria. J Clin Oncol 2007;25:17531759.

11 The biological activity of cediranib (AZD2171) in gastro-intestinal stromal tumours (GIST). NCT00385203. http://clinicaltrials.gov.

12 Evaluation of nilotinib in patients with advanced gastrointestinal stromal tumor (GIST). NCT01110668. http://clinicaltrials.gov.

13 Pazopanib in imatinib refractory or intolerant gastrointestinal stromal tumors (GIST). NCT01391611. http://clinicaltrials.gov. 


\section{Case Reports in Oncology}

\begin{tabular}{l|l}
\hline Case Rep Oncol 2013;6:579-584 \\
\hline DOI: $10.1159 / 000356998$ & $\begin{array}{l}\text { C 2013 S. Karger AG, Basel } \\
\text { www.karger.com/cro }\end{array}$ \\
\hline
\end{tabular}

Kafeel et al.: Esophageal Gastrointestinal Stromal Tumors Presenting as Mediastinal Mass

14 Regorafenib in patients with metastatic and/or unresectable gastrointestinal stromal tumor. NCT01068769. http://clinicaltrials.gov.

15 Park SH, Ryu MH, Ryoo BY, et al: Sorafenib in patients with metastatic gastrointestinal stromal tumors who failed two or more prior tyrosine kinase inhibitors: a phase II study of Korean gastrointestinal stromal tumors study group. Invest New Drugs 2012;30:2377-2383.

16 Joensuu H, DeMatteo RP: The management of gastrointestinal stromal tumors: a model for targeted and multidisciplinary therapy of malignancy. Annu Rev Med 2012;63:247-258.

17 Lee JR, Anstadt MP, Khwaja S, Green LK: Gastrointestinal stromal tumor of the posterior mediastinum. Eur J Cardiothorac Surg 2002;22:1014-1016.

18 Machishi H, Okada Y, Nagai M, Noda N, Hori T, Shimono T, Fukudome T: A rare case of huge gastrointestinal stromal tumor (GIST) of the stomach extending into the posterior mediastinum. Dig Dis Sci 2002;47:14921497.

19 Ertem M, Baca B, Dogusoy G, Erguney S, Yavuz N: Thoracoscopic enucleation of a giant submucosal tumor of the esophagus. Surg Laparosc Endosc Percutan Tech 2004;14:87-90.

20 Feakins RM, Mears L, Atkinson P, Hughes F: Oesophageal gastrointestinal stromal tumour masquerading as neuroendocrine carcinoma. Histopathology 2005;47:327-329.

-21 Gouveia AM, Pimenta AP, Lopes JM, Capelinha AF, Ferreira SS, Valbuena C, Oliveira MC: Esophageal GIST: therapeutic implications of an uncommon presentation of a rare tumor. Dis Esophagus 2005;18:70-73. Manu N, Richard P, Howard S: Bleeding esophageal GIST. Dis Esophagus 2005;18:281-282.

23 Portale G, Zaninotto G, Costantini M, Rugge M, Pennelli GM, Rampado S, Bocus P, Ancona E: Esophageal GIST: case report of surgical enucleation and update on current diagnostic and therapeutic options. Int J Surg Pathol 2007;15:393-396.

24 Milman S, Kim AW, Farlow E, Liptay MJ: Enucleation of a giant esophageal gastrointestinal stromal tumor. Ann Thorac Surg 2009;87:1603-1605.

25 Kim JM, Yoon YH, Lee KH, Kim JH: Malignant gastrointestinal stromal tumour in the posterior mediastinum. Interact Cardiovasc Thorac Surg 2012;14:497-499.

Table 1. Summary of esophageal GIST presentations and review of the literature

\begin{tabular}{lllllll}
\hline Date & $\begin{array}{l}\text { Study } \\
\text { (first author) }\end{array}$ & Presenting complaint & $\begin{array}{l}\text { Age, } \\
\text { years }\end{array}$ & $\begin{array}{l}\text { Affected organ or } \\
\text { area }\end{array}$ & Size, cm \\
\hline 2002 & Lee [17] & $\begin{array}{l}\text { Incidental: routine chest X-ray (during an } \\
\text { evaluation for trauma) }\end{array}$ & 64 & $\mathrm{~m}$ & Esophageal & 9 \\
& & & & & & \\
2002 & Machishi [18] & Anorexia and back pain & 61 & $\mathrm{f}$ & Gastric & 20 , width \\
2004 & Ertem [19] & Weight loss + regurgitation & 46 & $\mathrm{~m}$ & Mid esophagus & 8 \\
2005 & Feakins [20] & Dysphagia & 36 & $\mathrm{f}$ & Mid esophagus & 7 \\
2005 & Gouveia [21] & Incidental: routine echocardiogram & 59 & $\mathrm{~m}$ & Esophageal & $13.5 \times 8.5 \times 7.6$ \\
2005 & Manu [22] & Melena + dizziness & 75 & $\mathrm{~m}$ & Lower esophagus & $14 \times 7 \times 4$ \\
2005 & Chang [8] & Dysphagia & 36 & $\mathrm{~m}$ & Lower esophagus & 6.5 \\
2006 & Basoglu [4] & Dyspnea + dysphagia + back pain & 33 & $\mathrm{f}$ & Thoracic esophagus & 27 \\
2007 & Portale [23] & Melena + hematemesis & 66 & $\mathrm{f}$ & Lower esophagus & 3.5 \\
2009 & Milman [24] & Incidental: CT workup for nephrolithiasis & 82 & $\mathrm{~m}$ & Distal esophagus & $11.0 \times 8.0 \times 4.0$ \\
2012 & Kim [25] & Chest pain + epigastric discomfort + nuchal pain 71 & $\mathrm{f}$ & Lower esophagus & $10.0 \times 8.0$ \\
\hline
\end{tabular}




\section{Case Reports in Oncology}

\begin{tabular}{l|l}
\hline \multicolumn{2}{l}{ Case Rep Oncol 2013;6:579-584 } \\
\hline DOI: $10.1159 / 000356998$ & $\begin{array}{l}\text { C 2013 S. Karger AG, Basel } \\
\text { www.karger.com/cro }\end{array}$ \\
\hline
\end{tabular}

Kafeel et al.: Esophageal Gastrointestinal Stromal Tumors Presenting as Mediastinal Mass

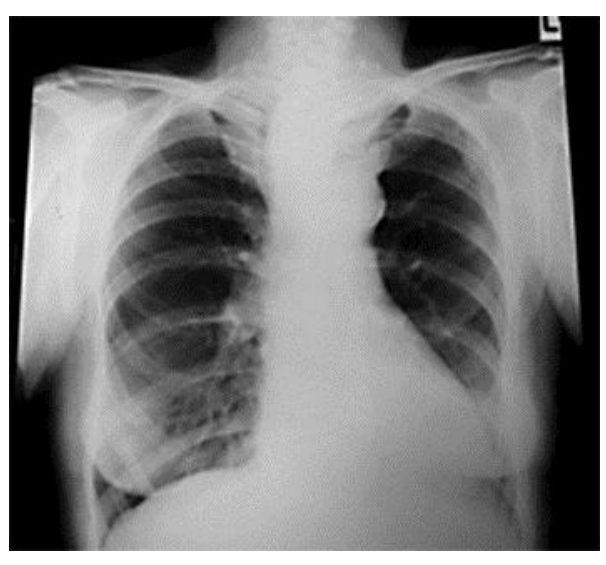

Fig. 1. Chest X-ray shows a posterior mediastinal mass.

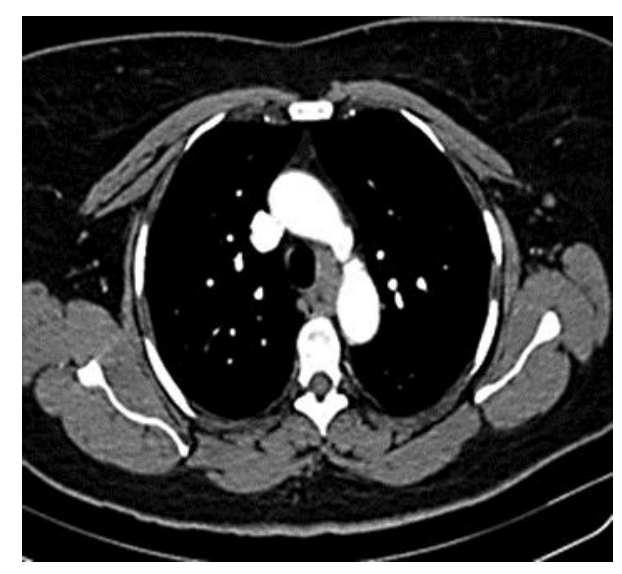

Fig. 2. Chest CT shows a posterior mediastinal mass.

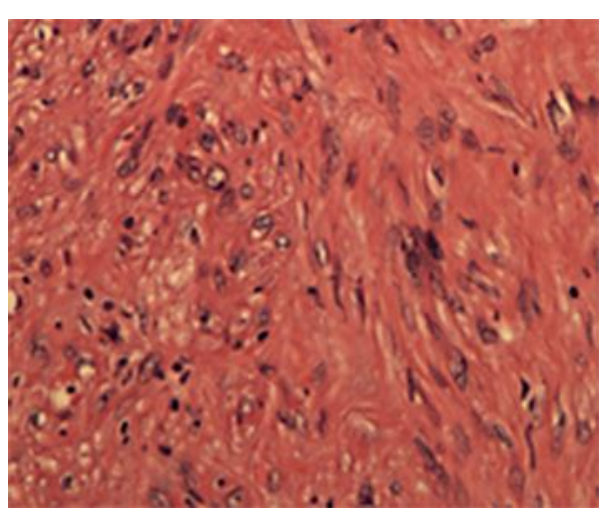

Fig. 3 . Tumor tissue with spindle-shaped cells. Original magnification, $\times 40$. 


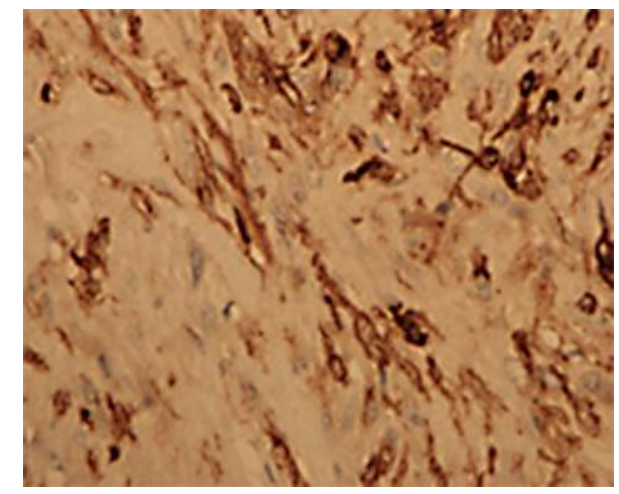

Fig. 4. Tumor tissue with spindle cells confirmed as GISTs with CD117 immunostaining. 